\title{
Grup Automorfisma Graf Tangga dan Graf Lingkaran
}

\author{
Muhammad Abdy ${ }^{1, \text { a) }}$, Wahidah Sanusi ${ }^{1, b)}$, dan Armansyah ${ }^{1, c)}$ \\ ${ }^{1}$ Jurusan Matematika FMIPA Universitas Negeri Makassar, 90224 \\ a) muh.abdy@unm.ac.id \\ b)wahidah.sanusi@unm.ac.id \\ c) arman97.syah@gmail.com
}

\begin{abstract}
Abstrak. Automorfisma dari suatu graf $G$ merupakan isomorfisma dari graf $G$ ke dirinya sendiri, yaitu fungsi yang memetakan dirinya sendiri. Automorfisma suatu graf dapat dicari dengan menentukan semua kemungkinan fungsi yang satu-satu, onto serta isomorfisma dari himpunan titik pada graf tersebut. Artikel ini difokuskan pada penentuan banyaknya fungsi pada graf tangga dan graf lingkaran yang automorfisma serta grup yang dibentuk oleh himpunan automorfisma dari kedua graf tersebut. Jenis penelitian ini merupakan penelitian dasar atau penelitian murni dan metode yang digunakan adalah studi literatur. Hasil penelitian ini menunjukkan bahwa graf tangga $L_{1}$ membentuk grup abelian berorde-2, graf tangga $L_{2}$ membentuk grup dihedral berorde-8, dan graf tangga $L_{n}, n \geq 3$ membentuk grup abelian berorde- 4 . Sedangkan graf lingkaran $C_{n}, n \geq 3$, membentuk grup dihedral berorde- $2 n$.
\end{abstract}

Kata Kunci: Automorfisma, Graf Lingkaran, Graf Tangga, Grup

\begin{abstract}
An automorphism of a graph $G$ is an isomorphism of graph $G$ to itself i.e. the function that maps onto itself. An automorphism of a graph can be looked for by determining all possible functions which is one-to-one, onto, and isomorphism from vertex set at the graph. This article is focused on determining the number of automorphism functions on ladder graph and cycle graph and the groups formed by the two graphs. The tipe of this research is basic research or pure research and the research method used is literarture review. The result show that ladder graph $L_{1}$ forms an abelian group of order 2, ladder graph $L_{2}$ forms a dihedral group of order 8 , and ladder graph $L_{n}, n \geq 3$ forms an abelian group of order 4 . In other side, cycle graph $C_{n}, n \geq 3$ forms a dihedral group of order $2 n$.
\end{abstract}

Keywords: Automorphism, Cycle Graph, Ladder Graph, Group

\section{PENDAHULUAN}

Teori graf merupakan salah satu cabang matematika yang berkembang sangat pesat, sehingga dalam perkembangannya banyak yang menyejajarkannya dengan aljabar yang lebih dahulu berkembang (Hasanah, 2008). Pembahasan teori graf sangat menarik karena keunikannya dan banyak penerapannya dalam menyelesaikan berbagai permasalahan. Suatu permasalahan dapat dibuat sederhana jika merumuskannya menggunakan teori graf, yaitu dengan mengambil aspekaspek yang perlu dan membuang aspek-aspek lainnya. (Purwanto, 1998).

Salah satu topik kajian yang menarik pada teori graf adalah tentang automorfisma graf. Automorfisma graf merupakan suatu permutasi dari himpunan titik-titik $V(G)$ atau himpunan sisisisi $E(G)$ dari graf $G$ (Chartrand \& Lesniak, 1996). Untuk mencari automorfisma suatu graf, 
biasanya dengan menentukan semua kemungkinan fungsi yang satu-satu, onto, dan isomorfisma dari himpunan titik pada graf tersebut.

Beberapa peneliti telah melakukan penelitian tentang automorfisma pada graf. Fitriyah (2011) memperlihatkan bagaimana automorfisma graf roda pada $W_{n}$ dan graf tangga pada $L_{2}$ dan $L_{3}$ serta bagaimana pola fungsi pada graf tersebut. Penelitian lainnya dilakukan oleh Damayanti (2011) yang memperlihatkan bentuk automorfisma graf bintang dan graf lintasan. Dalam penelitian tersebut juga menunjukkan grup yang dibentuk dari himpunan semua automorfisma pada graf.

Penelitian ini mengembangkan hasil penelitian Fitriyah, yaitu mencari bentuk automorfisma pada graf lingkaran pada $L_{1}$ sampai $L_{n}$ dengan menambahkan graf lain yaitu graf lingkaran. Selain itu, penelitian ini juga mencari bentuk grup pada himpunan semua automorfisma graf tangga dan graf lingkaran dengan menggunakan metode pada penelitian Damayanti. Oleh karena itu, penulis meneliti Grup Automorfisma Graf Tangga dan Graf Lingkaran.

\section{LANDASAN TEORI}

\section{Grup}

Suatu sistem aljabar $(G, *)$ dari himpunan tidak kosong $G$ dengan operasi biner *, dikatakan grup jika memenuhi sifat berikut (Tahmir, 2004):

1. $\forall a, b, c \in G$ berlaku $a *(b * c)=(a * b) * c$ (Sifat asosiatif);

2. ada $e \in G$ sehingga $\forall a \in G$ berlaku $a * e=e * a=a$ (adanya unsur identitas di G);

3. $\forall a \in G$ ada $a^{-1} \in G$ sehingga $a * a^{-1}=a^{-1} * a=e$ (adanya unsur invers setiap anggota di G).

Jika $(G, *)$ merupakan grup yang memenuhi sifat komutatif yaitu $a * b=b * a \forall a, b \in G$, maka $\mathrm{G}$ disebut grup komutatif. Himpunan simetri-simetri dari segi- $n$ beraturan dinotasikan dengan $D_{2 n}, \forall n \in \mathbb{Z}^{+}$dan $n \geq 3$, dengan operasi komposisi " 。" yang memenuhi aksioma-aksioma grup disebut grup dihedral (Dammit \& Foote, 1991).

\section{Graf}

Sebuah graf $\mathrm{G}$ berisikan dua himpunan yaitu himpunan hingga tak kosong $\mathrm{V}(\mathrm{G})$ yang elemenelemennya disebut titik dan himpunan hingga (mungkin kosong) $\mathrm{E}(\mathrm{G})$ yang elemen-elemennya disebut sisi sedemikian hingga setiap elemen $e$ dalam $\mathrm{E}(\mathrm{G})$ adalah sebuah pasangan tak berurutan dari titik-titik di $V(G)$. $V(G)$ disebut himpunan titik dari $G$ dan $E(G)$ disebut himpunan sisi dari G (Budayasa, 2008).

\section{Graf Tangga}

Graf yang dibentuk dari hasil kali kartesius graf lintasan dengan dua titik dan graf lintasan $\mathrm{n}$ titik. Graf tangga dinotasikan dengan $L_{n}$, sehingga $L_{n}=P_{2} \times P_{n}$ (Gallian, 2007).

\section{Graf Lingkaran}

Graf Lingkaran (Cycle Graph) $C_{n}$ adalah graf terhubung beraturan 2 yang mempunyai $n$ titik $(n \geq 3)$ dan $n$ sisi (Chartrand \& Lesniak, 1986).

\section{Automorfisma Graf}

Automorfisma graf $\mathrm{G}$ adalah isomorfisma dari graf $\mathrm{G}$ ke $\mathrm{G}$ sendiri. Dengan kata lain isomorfisma dari $\mathrm{G}$ merupakan permutasi himpunan titik-titk $V(G)$ atau sisi-sisi $\mathrm{E}(\mathrm{G})$. Jika $\varphi$ adalah automorfisma graf $G$ dan $v \in V(G)$ maka $\operatorname{deg} \varphi(v)=\operatorname{deg} v$ (Chartrand \& Lesniak, 1996). 
Fitriyah (2011) mengemukakan bahwa pada graf tangga- $n\left(L_{n}\right)$ tidak semua fungsi yang satusatu dan onto membentuk automorfisma. Sedangkan untuk fungsi identitas pasti akan membentuk automorfisma. Jika banyaknya fungsi yang automorfisma tidak membagi banyaknya semua kemungkinan satu-satu dan onto, maka fungsi tersebut tidak membentuk grup karena tidak tertutup.

\section{METODE PENELITIAN}

Penelitian ini adalah penelitian dasar atau murni. Metode yang digunakan adalah studi literatur. Fokus kajian penelitian ini ialah menunjukkan automorfisma pada graf tangga dan graf lingkaran serta grup yang dibentuk oleh himpunan automorfisma kedua graf tersebut. Penelitian ini diawali dengan menggambarkan dan memberi label graf tangga dan graf lingkaran kemudian menentukan semua permutasi yang mungkin dan memilih permutasi yang automorfisma. Selanjutnya, membangun teorema tentang banyak automorfisma dan bentuk permutasinya serta menunjukkan bahwa himpunan automorfisma tersebut membentuk grup.

\section{HASIL PENELITIAN}

\section{Automorfisma Graf Tangga}

\section{Lemma 1}

Terdapat 2 automorfisma graf tangga $L_{1}$, yaitu:

$\alpha_{1}=\left(v_{1}\right)\left(v_{2}\right)$

$\alpha_{2}=\left(v_{1}, v_{2}\right)$

dan membentuk grup abelian berorde-2.

\section{Bukti:}

Graf $L_{1}$ memiliki 2 titik.

Misalkan titik-titiknya adalah $V\left(L_{1}\right)=\left\{v_{1}, v_{2}\right\}=\{1,2\}$

$\alpha_{1}=(1)(2) ; \alpha_{2}=(1,2)$ merupakan bentuk permutasi dari $L_{1}$ ke $L_{1}$.

Akan dibuktikan bahwa $\alpha_{1}$ dan $\alpha_{2}$ merupakan automorfisma.

1. $\alpha_{1}=(1)(2)$

Fungsi ini dapat dijelaskan bahwa $\alpha_{1}(1)=1$ dan $\alpha_{1}(2)=2$.

Perhatikan bahwa:

$(1,2) \in E\left(L_{1}\right)$

sehingga,

$\alpha(1,2)=(\alpha(1), \alpha(2))=(1,2) \in E\left(L_{1}\right)$

Jadi, $\alpha_{1}=(1)(2)$ merupakan automorfisma.

2. $\alpha_{2}=(1,2)$

Fungsi ini dapat dijelaskan bahwa $\alpha_{2}(1)=2$ dan $\alpha_{2}(2)=1$.

Perhatikan bahwa:

$(1,2) \in E\left(L_{1}\right)$

sehingga,

$\alpha(1,2)=(\alpha(1), \alpha(2))=(2,1) \in E\left(L_{1}\right)$

Jadi, $\alpha_{2}=(1,2)$ merupakan automorfisma. 
TABEL 1. Tabel Cayley Automorfisma Graf Tangga-1 $\left(L_{1}\right)$

\begin{tabular}{lll}
\hline$\circ$ & $\alpha_{1}$ & $\alpha_{2}$ \\
\hline$\alpha_{1}$ & $\alpha_{1}$ & $\alpha_{2}$ \\
$\alpha_{2}$ & $\alpha_{2}$ & $\alpha_{1}$ \\
\hline
\end{tabular}

Berdasarkan Tabel 1 diperoleh $\mathcal{A}\left(L_{1}\right)=\left(\alpha_{1}, \alpha_{2}\right)$ terhadap operasi komposisi fungsi $\circ$ atau $\left(\mathcal{A}\left(L_{1}\right), \circ\right)$ merupakan grup. $\left(\mathcal{A}\left(L_{1}\right), \circ\right)$ merupakan grup berorde-2, dimana $\alpha_{m} \circ \alpha_{n}=\alpha_{n} \circ \alpha_{m}, \forall \alpha_{m}, \alpha_{n} \in \mathcal{A}\left(L_{1}\right)$ sehingga terbukti bahwa graf tangga $L_{1}$ membentuk grup abelian berorde- 2 .

\section{Lemma 2}

Terdapat 8 automorfisma graf tangga $L_{2}$, yaitu:

$$
\begin{aligned}
& \mu_{1}=\left(v_{1}\right)\left(v_{2}\right)\left(v_{3}\right)\left(v_{4}\right) \\
& \mu_{2}=\left(v_{1}\right)\left(v_{2} v_{3}\right)\left(v_{4}\right) \\
& \mu_{3}=\left(v_{1} v_{4}\right)\left(v_{2}\right)\left(v_{3}\right) \\
& \mu_{4}=\left(v_{1} v_{2}\right)\left(v_{3} v_{4}\right) \\
& \mu_{5}=\left(v_{1} v_{3}\right)\left(v_{2} v_{4}\right) \\
& \mu_{6}=\left(v_{1} v_{4}\right)\left(v_{2} v_{3}\right) \\
& \mu_{7}=\left(v_{1} v_{3} v_{4} v_{2}\right) \\
& \mu_{8}=\left(v_{1} v_{2} v_{4} v_{3}\right)
\end{aligned}
$$

dan membentuk grup dihedral berorde-8 $\left(D_{4}\right)$

\section{Bukti:}

Graf $L_{2}$ memiliki 4 titik.

Misalkan titik-titiknya adalah $V\left(L_{2}\right)=\left\{v_{1}, v_{2}, v_{3}, v_{4}\right\}=\{1,2,3,4\}$.

$\mu_{1}=(1)(2)(3)(4) ; \mu_{2}=(1)(2,3)(4) ; \mu_{3}=(1,4)(2)(3) ; \mu_{4}=(1,2)(3,4) ; \mu_{5}=(1,3)(2,4) ;$ $\mu_{6}=(1,4)(2,3) ; \mu_{7}=(1,3,4,2) ; \mu_{8}=(1,2,4,3)$ merupakan bentuk permutasi dari $L_{2}$ ke $L_{2}$.

Akan dibuktikan bahwa $\mu_{1}, \mu_{2}, \mu_{3}, \mu_{4}, \mu_{5}, \mu_{6}, \mu_{7}$ dan $\mu_{8}$ merupakan automorfisma.

1. $\mu_{1}=(1)(2)(3)(4)$

Fungsi $\mu_{1}$ merupakan automorfisma karena dapat ditunjukkan bahwa $(1,2) \in E\left(L_{2}\right) \rightarrow$ $\left(\mu_{1}(1), \mu_{1}(2)\right) \in E\left(L_{2}\right)$. Begitu juga dengan sisi yang lain pada $L_{2}$.

Hal yang sama juga berlaku untuk $\mu_{2}=(1)(2,3)(4) ; \mu_{3}=(1,4)(2)(3) ; \mu_{4}=(1,2)(3,4)$; $\mu_{5}=(1,3)(2,4) ; \mu_{6}=(1,4)(2,3) ; \mu_{7}=(1,3,4,2) ; \mu_{8}=(1,2,4,3)$.

TABEL 2. Tabel Cayley Automorfisma Graf Tangga-2 $\left(L_{2}\right)$

\begin{tabular}{ccccccccc}
\hline$\circ$ & $\mu_{1}$ & $\mu_{2}$ & $\mu_{3}$ & $\mu_{4}$ & $\mu_{5}$ & $\mu_{6}$ & $\mu_{7}$ & $\mu_{8}$ \\
\hline$\mu_{1}$ & $\mu_{1}$ & $\mu_{2}$ & $\mu_{3}$ & $\mu_{4}$ & $\mu_{5}$ & $\mu_{6}$ & $\mu_{7}$ & $\mu_{8}$ \\
$\mu_{2}$ & $\mu_{2}$ & $\mu_{1}$ & $\mu_{6}$ & $\mu_{8}$ & $\mu_{7}$ & $\mu_{3}$ & $\mu_{5}$ & $\mu_{4}$ \\
$\mu_{3}$ & $\mu_{3}$ & $\mu_{6}$ & $\mu_{1}$ & $\mu_{7}$ & $\mu_{8}$ & $\mu_{2}$ & $\mu_{4}$ & $\mu_{5}$ \\
$\mu_{4}$ & $\mu_{4}$ & $\mu_{7}$ & $\mu_{8}$ & $\mu_{1}$ & $\mu_{6}$ & $\mu_{5}$ & $\mu_{2}$ & $\mu_{3}$ \\
$\mu_{5}$ & $\mu_{5}$ & $\mu_{8}$ & $\mu_{7}$ & $\mu_{6}$ & $\mu_{1}$ & $\mu_{4}$ & $\mu_{3}$ & $\mu_{2}$ \\
$\mu_{6}$ & $\mu_{6}$ & $\mu_{3}$ & $\mu_{2}$ & $\mu_{5}$ & $\mu_{4}$ & $\mu_{1}$ & $\mu_{8}$ & $\mu_{7}$ \\
$\mu_{7}$ & $\mu_{7}$ & $\mu_{4}$ & $\mu_{5}$ & $\mu_{3}$ & $\mu_{2}$ & $\mu_{8}$ & $\mu_{6}$ & $\mu_{1}$ \\
$\mu_{8}$ & $\mu_{8}$ & $\mu_{5}$ & $\mu_{4}$ & $\mu_{2}$ & $\mu_{3}$ & $\mu_{7}$ & $\mu_{1}$ & $\mu_{6}$ \\
\hline
\end{tabular}

Berdasarkan Tabel 2 diperoleh $\mathcal{A}\left(L_{2}\right)=\left(\mu_{1}, \mu_{2}, \mu_{3}, \mu_{4}, \mu_{5}, \mu_{6}, \mu_{7}, \mu_{8}\right)$ terhadap operasi komposisi fungsi ○ atau $\left(\mathcal{A}\left(L_{2}\right), \circ\right)$ merupakan grup. $\left(\mathcal{A}\left(L_{2}\right), \circ\right)$ merupakan grup berorde-8 dan automorfisma $L_{2}$ diperoleh dari proses rotasi dan refleksi sehingga terbukti bahwa graf tangga $L_{2}$ membentuk grup dihedral berorde- 8 . 


\section{Teorema 1}

Graf Tangga $\left(L_{n}\right)$ dengan $2 n$ titik, $n \geq 3$ memiliki 4 fungsi yang automorfisma berbentuk

1. Untuk $n$ ganjil :

$$
\begin{aligned}
& \theta_{1}=\left(v_{1}\right)\left(v_{2}\right)\left(v_{3}\right) \ldots\left(v_{n}\right) \ldots\left(v_{2 n}\right) \\
& \theta_{2}=\left(v_{1} v_{2}\right)\left(v_{3} v_{4}\right) \ldots\left(v_{n} v_{n+1}\right) \ldots\left(v_{2 n-1} v_{2 n}\right) \\
& \theta_{3}=\left(v_{1} v_{2 n-1}\right)\left(v_{2} v_{2 n}\right)\left(v_{3} v_{2 n-3}\right)\left(v_{4} v_{2 n-2}\right) \ldots\left(v_{n}\right)\left(v_{n+1}\right) \\
& \theta_{4}=\left(v_{1} v_{2 n}\right)\left(v_{2} v_{2 n-1}\right)\left(v_{3} v_{2 n-2}\right) \ldots\left(v_{n} v_{n+1}\right)
\end{aligned}
$$

2. Untuk $n$ genap :

$$
\begin{aligned}
& \theta_{1}=\left(v_{1}\right)\left(v_{2}\right)\left(v_{3}\right) \ldots\left(v_{n}\right) \ldots\left(v_{2 n}\right) \\
& \theta_{2}=\left(v_{1} v_{2}\right)\left(v_{3} v_{4}\right) \ldots\left(v_{n-1} v_{n}\right) \ldots\left(v_{2 n-1} v_{2 n}\right) \\
& \theta_{3}=\left(v_{1} v_{2 n-1}\right)\left(v_{2} v_{2 n}\right)\left(v_{3} v_{2 n-3}\right)\left(v_{4} v_{2 n-2}\right) \ldots\left(v_{n} v_{n+2}\right) \\
& \theta_{4}=\left(v_{1} v_{2 n}\right)\left(v_{2} v_{2 n-1}\right)\left(v_{3} v_{2 n-2}\right) \ldots\left(v_{n} v_{n+1}\right)
\end{aligned}
$$

dan membentuk grup abelian berorde 4 .

\section{Bukti:}

Graf $L_{n}$ memiliki $2 n$ titik

Misalkan titik-titiknya adalah $V\left(L_{n}\right)=\left(v_{1} v_{2} v_{3} \ldots v_{n} \ldots v_{2 n}\right)$.

Misalkan $\theta$ adalah automorfisma $L_{n}$ ke dirinya sendiri.

Akan ditunjukkan $\theta_{1}, \theta_{2}, \theta_{3}$ dan $\theta_{4}$ merupakan automorfisma.

\section{Untuk n ganjil}

1. $\theta_{1}=\left(v_{1}\right)\left(v_{2}\right)\left(v_{3}\right) \ldots\left(v_{n}\right) \ldots\left(v_{2 n}\right)$

$\theta_{1}$ merupakan fungsi identitas sehingga jelas merupakan automorfisma

2. $\theta_{2}=\left(v_{1} v_{2}\right)\left(v_{3} v_{4}\right) \ldots\left(v_{n} v_{n+1}\right) \ldots\left(v_{2 n-1} v_{2 n}\right)$

Diketahui $\left(v_{1}, v_{2}\right),\left(v_{1}, v_{3}\right),\left(v_{2}, v_{4}\right),\left(v_{3}, v_{4}\right), \ldots,\left(v_{n}, v_{n+1}\right), \ldots,\left(v_{2 n-1}, v_{2 n}\right) \in E\left(L_{n}\right)$

$\theta_{2}$ merupakan automorfisma karena dapat ditunjukkan bahwa

$$
\left(v_{p}, v_{q}\right) \in E\left(L_{n}\right) \rightarrow\left(\theta\left(v_{p}\right), \theta\left(v_{q}\right)\right) \in E\left(L_{n}\right) \forall v_{p}, v_{q} \in V\left(L_{n}\right)
$$

Hal yang sama juga berlaku untuk fungsi berikut:

$\theta_{3}=\left(v_{1} v_{2 n-1}\right)\left(v_{2} v_{2 n}\right)\left(v_{3} v_{2 n-3}\right)\left(v_{4} v_{2 n-2}\right) \ldots\left(v_{n}\right)\left(v_{n+1}\right)$

$\theta_{4}=\left(v_{1} v_{2 n}\right)\left(v_{2} v_{2 n-1}\right)\left(v_{3} v_{2 n-2}\right) \ldots\left(v_{n} v_{n+1}\right)$

\section{Untuk $\mathrm{n}$ genap}

1. $\theta_{1}=\left(v_{1}\right)\left(v_{2}\right)\left(v_{3}\right) \ldots\left(v_{n}\right) \ldots\left(v_{2 n}\right)$

$\theta_{1}$ merupakan fungsi identitas sehingga jelas merupakan automorfisma

2. $\theta_{2}=\left(v_{1} v_{2}\right)\left(v_{3} v_{4}\right) \ldots\left(v_{n-1} v_{n}\right) \ldots\left(v_{2 n-1} v_{2 n}\right)$

Diketahui $\left(v_{1}, v_{2}\right),\left(v_{1}, v_{3}\right),\left(v_{2}, v_{4}\right),\left(v_{3}, v_{4}\right), \ldots,\left(v_{n}, v_{n+1}\right), \ldots,\left(v_{2 n-1}, v_{2 n}\right) \in E\left(L_{n}\right)$

$\theta_{2}$ merupakan automorfisma karena dapat ditunjukkan bahwa

$$
\left(v_{p}, v_{q}\right) \in E\left(L_{n}\right) \rightarrow\left(\theta\left(v_{p}\right), \theta\left(v_{q}\right)\right) \in E\left(L_{n}\right) \forall v_{p}, v_{q} \in V\left(L_{n}\right)
$$

Hal yang sama juga berlaku untuk fungsi berikut:

$$
\begin{aligned}
& \theta_{3}=\left(v_{1} v_{2 n-1}\right)\left(v_{2} v_{2 n}\right)\left(v_{3} v_{2 n-3}\right)\left(v_{4} v_{2 n-2}\right) \ldots\left(v_{n} v_{n+2}\right) \\
& \theta_{4}=\left(v_{1} v_{2 n}\right)\left(v_{2} v_{2 n-1}\right)\left(v_{3} v_{2 n-2}\right) \ldots\left(v_{n} v_{n+1}\right)
\end{aligned}
$$


TABEL 3. Tabel Cayley $\left(\left(L_{n}\right), \circ\right)$

\begin{tabular}{ccccc}
\hline$\circ$ & $\theta_{1}$ & $\theta_{2}$ & $\theta_{3}$ & $\theta_{4}$ \\
\hline$\theta_{1}$ & $\theta_{1}$ & $\theta_{2}$ & $\theta_{3}$ & $\theta_{4}$ \\
$\theta_{2}$ & $\theta_{2}$ & $\theta_{1}$ & $\theta_{4}$ & $\theta_{3}$ \\
$\theta_{3}$ & $\theta_{3}$ & $\theta_{4}$ & $\theta_{1}$ & $\theta_{2}$ \\
$\theta_{4}$ & $\theta_{4}$ & $\theta_{3}$ & $\theta_{2}$ & $\theta_{1}$ \\
\hline
\end{tabular}

Berdasarkan Tabel 3 diperoleh $\mathcal{A}\left(L_{n}\right)=\left(\theta_{1}, \theta_{2}, \theta_{3}, \theta_{4}\right)$ terhadap operasi komposisi fungsi $\circ$ atau $\left(\mathcal{A}\left(L_{n}\right), \circ\right)$ merupakan grup. $\left(\mathcal{A}\left(L_{n}\right), \circ\right)$ merupakan grup berorde-4, dimana $\theta_{m} \circ \theta_{n}=\theta_{n} \circ$ $\theta_{m}, \forall \theta_{m}, \theta_{n} \in \mathcal{A}\left(L_{n}\right)$ sehingga terbukti bahwa graf tangga $L_{n}$ membentuk grup abelian berorde4.

\section{Automorfisma Graf Lingkaran}

\section{Teorema 2}

Graf Lingkaran $C_{n}$ dengan $n$ titik memiliki $2 n$ fungsi yang automorfisma dan membentuk grup dihedral berorde- $2 \mathrm{n}$

\section{Bukti:}

Graf $C_{n}$ memiliki $n$ titik dengan $n \geq 3$.

Misalkan titik-titiknya adalah $V\left(C_{n}\right)=\left(v_{1} v_{2} v_{3} \ldots v_{n}\right)$.

Berdasarkan definisi, graf lingkaran $C_{n}$ merupakan graf terhubung beraturan 2 yang berarti setiap titik di $C_{n}$ berderajat 2 dan setiap dua titik yang berbeda terdapat lintasan (path) yang menghubungkan titik tersebut dan membentuk jalan tertutup. Dengan demikian, automorfisma graf lingkaran dapat diperoleh dengan cara rotasi dan refleksi.

Misalkan rotasi dilakukan searah jarum jam, maka setiap titik $C_{n}$ dapat dirotasi sebesar $\left(\frac{360}{n} k\right)^{\circ}$ untuk $k=1,2,3, \ldots, n$. Dengan demikian, banyaknya permutasi yang mungkin dari proses rotasi adalah sebanyak $n$

Untuk proses refleksi, jika $n$ ganjil maka pencerminan dapat dilakukan terhadap simetri yang dibentuk titik-titik $C_{n}$ sehingga banyaknya permutasi yang mungkin sebanyak $n$. Jika $n$ genap maka pencerminaan terhadap titik dan sisi $C_{n}$ sebanyak $\frac{n}{2}$ dan pencerminaan terhadap diagonal sebanyak $\frac{n}{2}$, sehingga banyaknya permutasi yang mungkin juga sebanyak $n$. Dengan demikian, banyak permutasi yang mungkin dari proses refleksi adalah sebanyak $n$.

Berdasarkan proses rotasi dan refleksi diperoleh banyaknya automorfisma pada graf lingkaran $C_{n}$ yaitu $n+n=2 n$. Dengan demikian graf lingkaran merupakan anggota himpunan dari grup dihedral karena dibangun dari proses rotasi dan refleksi, sehingga terbukti bahwa grup automorfisma graf lingkaran $C_{n}$ grup dihedral berorde- $2 n$.

\section{KESIMPULAN}

1. Graf Tangga-1 $\left(L_{1}\right)$ dengan 2 titik memiliki 2 fungsi yang automorfisma dan membentuk grup abelian berorde-2

2. Graf Tangga-2 $\left(L_{2}\right)$ dengan 4 titik memiliki 8 fungsi yang automorfisma dan membentuk grup dihedral berorde-8 $\left(D_{4}\right)$ 
3. Graf Tangga- $n\left(L_{n}\right)$ dengan $2 n$ titik . $n \geq 3$ memiliki 4 fungsi yang automorfisma berbentuk:

Untuk n ganjil :

$\theta_{1}=\left(v_{1}\right)\left(v_{2}\right)\left(v_{3}\right) \ldots\left(v_{n}\right) \ldots\left(v_{2 n}\right)$

$\theta_{2}=\left(v_{1} v_{2}\right)\left(v_{3} v_{4}\right) \ldots\left(v_{n} v_{n+1}\right) \ldots\left(v_{2 n-1} v_{2 n}\right)$

$\theta_{3}=\left(v_{1} v_{2 n-1}\right)\left(v_{2} v_{2 n}\right)\left(v_{3} v_{2 n-3}\right)\left(v_{4} v_{2 n-2}\right) \ldots\left(v_{n}\right)\left(v_{n+1}\right)$

$\theta_{4}=\left(\mathrm{v}_{1} \mathrm{v}_{2 \mathrm{n}}\right)\left(\mathrm{v}_{2} \mathrm{v}_{2 \mathrm{n}-1}\right)\left(\mathrm{v}_{3} \mathrm{v}_{2 \mathrm{n}-2}\right) \ldots\left(\mathrm{v}_{\mathrm{n}} \mathrm{v}_{\mathrm{n}+1}\right)$

Untuk n genap :

$\theta_{1}=\left(v_{1}\right)\left(v_{2}\right)\left(v_{3}\right) \ldots\left(v_{n}\right) \ldots\left(v_{2 n}\right)$

$\theta_{2}=\left(\mathrm{v}_{1} \mathrm{v}_{2}\right)\left(\mathrm{v}_{3} \mathrm{v}_{4}\right) \ldots\left(\mathrm{v}_{\mathrm{n}-1} \mathrm{v}_{\mathrm{n}}\right) \ldots\left(\mathrm{v}_{2 \mathrm{n}-1} \mathrm{v}_{2 \mathrm{n}}\right)$

$\theta_{3}=\left(\mathrm{v}_{1} \mathrm{v}_{2 \mathrm{n}-1}\right)\left(\mathrm{v}_{2} \mathrm{v}_{2 \mathrm{n}}\right)\left(\mathrm{v}_{3} \mathrm{v}_{2 \mathrm{n}-3}\right)\left(\mathrm{v}_{4} \mathrm{v}_{2 \mathrm{n}-2}\right) \ldots\left(\mathrm{v}_{\mathrm{n}} \mathrm{v}_{\mathrm{n}+2}\right)$

$\theta_{4}=\left(v_{1} v_{2 n}\right)\left(v_{2} v_{2 n-1}\right)\left(v_{3} v_{2 n-2}\right) \ldots\left(v_{n} v_{n+1}\right)$

dan membentuk grup abelian berorde 4 .

4. Graf Lingkaran- $n$ dengan $n$ titik, $n \geq 3$ memiliki $2 n$ fungsi yang automorfisma dan membentuk grup dihedral berorde- $2 n$.

\section{DAFTAR PUSTAKA}

Budayasa, K. (2008). Matematika Diskrit. Surabaya: UNESA University Press.

Chartrand, G., \& Lesniak, L. (1986). Graphs and Disgraphs Second Edition. California: A Devition of Wadsworth.

Chartrand, G., \& Lesniak, L. (1996). Graphs and Disgraphs Third Edition. California: A Devition of Wadsworth.

Damayanti, R. T. (2011). Automorfisma Graf Bintang dan Graf Lintasan (Skripsi). Universitas Negeri Maulana Malik Ibrahim, Malang.

Dammit, D. S., \& Foote, R. M. (1991). Abstract Algebra. New Jersey: Prentice-Hall, Inc.

Fitriyah, A. T. (2011). Automorfisme Graf Roda dan Graf Tangga (Skripsi). Universitas Islam Negeri Maulana Malik Ibrahim, Malang.

Gallian, J. A. (2007). A Dinamic Survey of Graf Labeling. The Electronic Journal of Combinatorics, 14.12-13.

Hasanah, S. (2008). Disgraf dari Tabel Cayley Grup Dihedral (Skripsi). Universitas Islam Negeri Maulana Malik Ibrahim, Malang.

Purwanto. (1998). Teori Graf. Malang: IKIP Malang.

Tahmir, S. (2004). Teori Grup. Makassar: Andira Publisher. 